\title{
ÇEŞİTLİ GIDA NUMUNELERİNİN IŞINLANIP IŞINLANMADIĞININ TERMOLÜMİNESANS (TL) TEKNİĞİ İLE BELİRLENMESİ KONUSUNDA YAPILAN BİR ULUSLARARASI KARŞILAŞTIRMA ÇALIŞMASI
}

\author{
Ülkü Rabia Yüce*, Talat Aydın \\ Türkiye Enerji, Nükleer ve Maden Araştırmaları Kurumu (TENMAK), Nükleer Enerji Araştırma Enstitüsü, \\ Kahramankazan, Ankara, Türkiye
}

Geliş / Received: 23.06.2020; Kabul / Accepted: 19.12.2020; Online bask1 / Published online: 30.12.2020

Yüce, Ü.R., Aydın, T. (2021). Çeşitli gıda numunelerinin ışınlanıp ışınlanmadığının termolüminesans (TL) tekniği ile belirlenmesi konusunda yapılan bir uluslararası karşılaştırma çalışması. GIDA (2021) 46 (1) 97 109 doi: 10.15237 /gida. GD20084.

Yüce, Ü.R., Aydm, T. (2021). An international comparison study determination whether various food samples have been irradiated using thermoluminescence (TL) technique. GIDA (2021) 46 (1) 97-109 doi: 10.15237/gida. GD20084.

\section{ÖZ}

Işınlanmış gıdaların tespiti için fiziksel, kimyasal veya biyolojik birçok yöntem vardır. Bu yöntemler içinde ışınlamadan yıllar sonra bile güvenilir sonuçlar veren ve sadece ışınlanmış gıdaları değil, daha önce hiç ışınlanmamış gıdalan da tespit edebilen fiziksel yöntem şimdilik sadece Termolüminesans (TL) yöntemidir. $\mathrm{Bu}$ yöntem, üzerinden silikat mineralleri ayrıştırılabilen gıdalara uygulanabilmektedir. Bu makalede, termolüminesans tekniği kullanılarak tarçın, köri, yeşil mercimek, kurutulmuş mantar, ay çekirdeği, keklik otu ve yeşil çay örneklerinin ışınlanıp ışınlanmadığının tespiti için uluslararası bir karşılaştırma çalışması kapsamında yapılan deneylerin sonuçları sunulmuştur. Yukarıda adı geçen gıda maddelerinden TS EN 1788:2007 standardına göre ayrıştırlan silikat minerallerinin önce doğal TL 1şıma eğrileri (TL1) daha sonra aynı ömeklerin $1 \mathrm{kGy}$ beta radyasyon dozu aldıktan sonraki TL ışıma eğrileri (TL2) kaydedilmiştir. Bu eğrilere ait maksimum pik sıcaklık değerlerine ve eğrilerin altında kalan alanların oranlanına (TL1/TL2) bakılmıştur. Karşlaş̧ırma çalışması sonuç raporlarında, tüm örneklerin \%100 başarı ile "ışınlanmış" veya "ışınlanmamış" olarak tespit edildiği belirtilmiştir.

Anahtar kelimeler: Işınlanmış gıdaların tespiti, termolüminesans, uluslararası karşılaşırma

\section{AN INTERNATIONAL COMPARISON STUDY ON DETERMINATION WHETHER VARIOUS FOOD SAMPLES HAVE BEEN IRRADIATED USING THERMOLUMINESCENCE (TL) TECHNIQUE}

\begin{abstract}
There are many methods for the detection of irradiated foods. Among these methods, the only physical method that gives reliable results even many years after irradiation is Thermoluminescence (TL) method. In this article, results of the experiments conducted within the scope of an international comparison study to determine whether the samples of cinnamon, curry, green lentils, dried mushrooms, sunflower seeds, oregano and green tea were exposed to any irradiation process using thermoluminescence technique are presented. According to the TS EN 1788:2007, the natural (TL1)
\end{abstract}

\footnotetext{
${ }^{*}$ Yazışmalardan sorumlu yazar / Corresponding author

: ulkurabiayuce.semiz @tenmak.gov.tr,

(ग): (+90) 3128101705

国: (+90) 3128154395
}

Ülkü Rabia Yüce; ORCID no: 0000-0002-3301-2863

Talat Aydın; ORCID no: 0000-0002-3319-648X 
and $1 \mathrm{kGy}$ beta irradiated (TL2) TL glow curves of the silicate minerals separated from the abovementioned food samples were obtained. The peak temperatures at the maximum values of these curves and the ratios of the areas under the curves (TL1 / TL2) were examined. In the comparison study results reports, it was stated that all samples were detected as "irradiated" or "non-irradiated" with $100 \%$ success.

Keywords: Irradiated food, thermoluminescence, international comparison

\section{GİRIŞ}

Taze gida tüketmek elbette sağlık açısından çok önemlidir ve klymetli bir gereksinimdir. Ancak ürettiğimiz her gidayı taze bir şekilde tüketebilme imkânımız yoktur. Bu nedenle geçmişten bugüne kadar kurutma, tuzlama, dondurma ve mayalama gibi çeşitli gıda koruma yöntemleri geliştirilmiştir. Giderek artan dünya nüfusunun beslenme ihtiyacını karşılayabilmek için gelişen gıda endüstrisinde bu geleneksel koruma yöntemleri yetersiz kalmıştur. Gelişen teknoloji ile daha fazla gıdanın korunabilmesini sağlamak, insanları gıda kaynaklı hastalıklara karşı korumak, gidaların ithalat ve ihracatının daha kolay yapabilmesi adına gidaların raf ömrünü uzatmak ve artan gida kayıplarını azaltmak için geleneksel yöntemlere alternatif kimyasalların ve radyasyon işınlamasının kullanıldığı gıda koruma yöntemleri geliştirilmiştir (Engin vd., 2011). Gıda 1şınlama, yüksek enerjili gama ışınları, X-1şınları veya elektronların belli bir dozda g1daya verildiği bir koruma yöntemidir. Büyük boyutlu gidalara kısa zamanda ve hızlı bir şekilde uygulanabilmesi, daha az maliyetli olması, kimyasal koruma yöntemleri gibi gıdada kalıntı birakmaması, sağlığa zararlı tüm mikroorganizmalar üzerinde daha fazla etkili olması ve ambalajlanmış son ürüne de uygulanabilir olması gıda 1şınlama yönteminin diğer yöntemlere kıyasla üstünlükleridir (Bayram vd., 2004; Screiber vd., 1993).

Gıdaların iyi tarım ve iyi üretim yapıldıktan sonra insan sağlığına uygun koşullar sağlanarak tüketiciye sunulması asıl şarttır. $\mathrm{Bu}$ şartlardan sonra hala ihtiyaç varsa, insan sağllğına zararı yoksa gida 1şınlama yönetmeliğinde önerilen koşullarda doğru bir şekilde gerçekleştiriliyorsa ve tüketicinin menfaatine uygunsa gidalar 1şınlanabilir (Gıda Işınlama Yönetmeliği, 2019). Gıda ışınlamada, Co-60 (1.25 MeV) ve Cs-137 (0.66 MeV) gama 1şınlayıcılar, $10 \mathrm{MeV}$ enerjili elektronların kullanıldığ1 elektron hızlandırıcılar veya $5 \mathrm{MeV}^{\prime}$ e kadar hızlandırılmış elektronlardan üretilen X-ışınları kullanılmaktadır. Gıdalar bu kaynaklar ile ışınlandığında hiçbir şekilde radyoaktif olmazlar yani radyasyon yaymazlar. Dünya Sağlık Örgütü (WHO), Gıda ve Tarım Örgütü (FAO) ve Uluslararasi Atom Enerjisi Ajansı (IAEA) gibi kuruluşların önderliğinde yapılan gıda 1şınlama çalışmalanında, 10 kGy'lik doz değerine kadar olan işınlamalarda gidaların besin değerlerini yitirmediği belirtilmiştir. Buna ilaveten gıdaların şeklinin, tadının, kokusunun değişmediği ve tüketim açısından risk oluşturmadığ raporlanmıştır (Anonymous,1981; International Atomic Energy Agency, 1991). Gıdaların ışınlanması işlemi konusunda ülkemizde şimdilik iki ayrı tesis aktif olarak hizmet vermektedir. Bunlardan ilki Ankara Sarayköy'de bulunan Türkiye Enerji, Nükleer ve Maden Araşturmaları Kurumuna (TENMAK) bağl1 Nükleer Enerji Araştırma Enstitüsü (NÜKEN) bünyesinde faaliyet veren SVST-Co-60 işınlama cihaz1 kullanan, IV. kategori tote box tipi gama 1şınlama tesisidir. Diğer tesis ise Tekirdağ Çerkezköy'de bulunan yine aynı kategori ve tipteki JS9600 1şınlama cihazı kullanan Gamma Pak ışınlama tesisidir. $\mathrm{Bu}$ tesislerde çoğunlukla mikroorganizma açısından zengin olan baharatların ışınlanması yapılmaktadır. Işınlama ücretleri gıdanın kilogramı başına ve ışınlama doz miktarına göre belirlenmektedir.

Ülkemizde 1şınlanmasına izin verilen gıda grupları ve ortalama işınlama doz miktarlanı gıda ışınlama yönetmeliğinde her gıdanın özellikleri itibariyle belirlenmiştir. Yönetmelik gereğince ışınlanmış gida üzerinde yeşil renkte Radura sembolü (Şekil 1) ile etiketleme yapılması zorunludur. Ayrica gıdanın tamamı 1şınlanmamış, sadece bileşenlerinden bir kısmı ışılnlanmışsa paketin içindekiler bölümünde bu bileşen belirtilmelidir (G1da 1şınlama yönetmeliği, 2019).

Gıdaların doğru bir şekilde etiketlemesi, hem tüketicinin "1şınlama" ile gıda koruma işlemi 
yapıldığına dair bilgilendirilmesi hem de tüketiciye "1şınlanmış" veya "işıllanmamış" ürünü seçebilme şansını vermesi bakımından önemlidir. Maalesef bazı firmalar 1şınlama maliyeti ve zahmetinden kaçınmak için gıdayı ışınlanmış gibi etiketleyerek aslında hiçbir koruma işlemi yapmadan insan sağlı̆̆ını tehdit edebilecek gidaları (özellikle baharatları) raflara koyabilmektedir. Tersi bir durum yani ışıllanmış bir gıdanın ışınlanmamış gibi gösterilmesi ülkemizde çok karşılaştığımız bir durum değildir. Gıdaların doğru bir şekilde etiketlenip etiketlenmediğinin kontrolü için her gida türüne uygulanabilen tek bir yöntem yoktur. Bu nedenle birçok yöntem geliştirilmiştir. Ancak bu yöntemlerin çoğu, her zaman kesin sonuç veremediğinden "eleme" başka bir deyişle "tarama" yöntemi olarak kalmıştır. Bu yöntemler arasında eleme yöntemi olmayan ve kesin teşhis yöntemi olarak adlandırılan dört fiziksel bir kimyasal yöntem vardır. Ülkemizde Türk Standartlanı Enstitüsü (TSE) orijinal dili İngilizce olan bu yöntemlere ait olan standartları Türkçe olarak hazırlamakta ve kullanıcılara erişimlerini sağlamaktadır (Çizelge 1) (EN 13708, 2004; EN 1786, 1998; EN 1787, 2005; EN 1788, 2007 ve EN 1784, 2005).

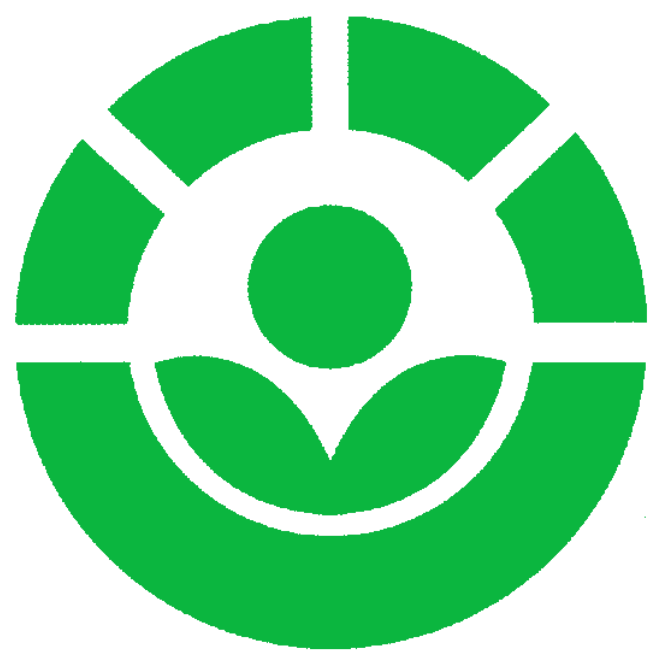

Şekil 1. Radura sembolü (G1da yönetmeliği, 2019) Figure1. Radura symbol (Food regulation, 2019)

Çizelge 1'de ilk sırada yer alan Termolüminesans (TL) yöntemi hariç diğer yöntemler sadece ışınlanmış gıdaları tespit edebilmektedir. TL yöntemi ise hem ışınlanmış hem de 1şınlanmamış gıdaların tespiti için kullanılmaktadır. $\mathrm{Bu}$ yöntemde teşhis için gıdanın kendisi değil gıda üzerine yapışmış inorganik toz tanecikleri (silikat mineralleri) incelenir. Bu yöntemle baharatlar, otlar, kuru meyveler ve sebzeler, kalsit içeren bazı kabuklu deniz ürünleri ve içerisinde silikat minerali bulunma ihtimali olan tüm gida karışımlarının 1şınlanıp 1şınlanmadığ belirlenebilmektedir (TS EN 1788,2007). Yöntemin en büyük avantaj1, 1şınlamadan sonra TL sinyallerinin yllarca kalabilmesidir (Anonymous,1981; International Atomic Energy Agency, 1991). Baz1 durumlarda gidadan TL tekniği ile ölçüm yapmaya imkân verebilecek miktarda silikat minerali toplanamaması, örnek hazırlama işleminin uzun sürmesi ve kullanılan kimyasalların pahalı olması yöntemin en önemli dezavantajlarıdır (Engin vd., 2011).

$\mathrm{Bu}$ makalede tarçın, köri, yeşil mercimek, kurutulmuş mantar, ay çekirdeği, keklik otu ve yeşil çay örneklerinin herhangi bir işınlama işlemine maruz kalıp kalmadığının TL tekniği kullanilarak belirlenmesi konusunda yapilan deneylerin sonuçları sunulmuştur. Bu araştırma İspanyada bulunan Centro Nacional de Alimentación (CNA) isimli araştırma merkezi tarafindan düzenlenen "Intercomparison exercises for quality assurance on physical methods for irradiated food detection" isimli uluslararası karşılaştırma çalışması kapsamında yapılmıştır. TS EN 1788:2007 standardı temel alınarak ayrıştırılan silikat minerallerinin önce doğal TL 1şıma eğrileri (TL1) daha sonra aynı örneklerin 1 kGy beta radyasyon dozu aldıktan sonraki TL 1şıma eğrileri (TL2) çizilmiştir. Bu eğrilerin pik maksimum sıcaklık değerlerine ve eğrilerin altında kalan alanların oranlarına (TL1/TL2) bakılmış ve İspanyadan gelen sonuç raporuna göre tüm örnekler $\% 100$ başarı ile "1şınlanmış" veya "işınlanmamış" olarak belirlenmiştir.

\section{MATERYAL VE YÖNTEM Termolüminesans}

Lüminesans olay1, yalitkan bir kristalin enerji bant diyagramı ile açıklanabilir (Şekil 2). Bu modelde elektronların, bant olarak adlandırılan farklı enerji seviyelerinde olduğu kabul edilir. En düşük enerji 
band1, değerlik band1 olarak, en yüksek enerji bandı iletim bandı ve bu iki bant arasındaki boşluk yasaklı bölge olarak adlandırlır. Kusursuz bir kristalde bu yasaklı bölgede hiç elektron bulunmaz. Ancak doğada gida maddeleri üzerindeki toz zerreciklerinde de en çok bulunan kuvars ve feldspat mineralleri gibi silisyum tabanlı silikat mineralleri başta olmak üzere çoğu mineral kristal yapılarının içinde bir takım kusurlar barındırırlar. Yapılarının içindeki bu kusurlar yasaklı bölgede yarı kararlı enerji seviyelerinin (elektronlar için tuzakların) oluşmasına neden olur (Aitken, 1985; Yüce, 2010).

Çizelge 1: Gıdaların ışınlanıp ışınlanmadığını belirleyebilen yöntemler.

Table 1. Methods that can determine whether foods have been irradiated

\begin{tabular}{|c|c|c|c|}
\hline $\begin{array}{l}\text { Sira } \\
\text { No }\end{array}$ & $\begin{array}{l}\text { G1da çeşidi } \\
\text { Food }\end{array}$ & $\begin{array}{l}\text { İlgili standart } \\
\text { Standard }\end{array}$ & $\begin{array}{l}\text { Tür/yöntem } \\
\text { Method }\end{array}$ \\
\hline 1 & $\begin{array}{l}\text { Baharatlar, otlar, } \\
\text { kuru meyveler, } \\
\text { sebzeler gibi silikat } \\
\text { minerali içeren } \\
\text { g1dalar } \\
\text { Foods containing } \\
\text { silicate mineral, such as } \\
\text { spices, herbs, dried } \\
\text { fruits, vegetables }\end{array}$ & $\begin{array}{l}\text { EN 1788:2007 Gıda Maddeleri- Silikat } \\
\text { Minerallerinin Ayrilabildiği Gidalarda Işınlanmanın } \\
\text { Belirlenmesi - Termolüminesans Yöntemi } \\
\text { EN 1788:2007 Foodstuffs - Thermoluminescence detection } \\
\text { of irradiated food from which silicate minerals can be isolated }\end{array}$ & $\begin{array}{l}\text { Fiziksel } \\
\text { Physical }\end{array}$ \\
\hline 2 & $\begin{array}{l}\text { Et, balı, tavuk, } \\
\text { deniz ürünleri gibi } \\
\text { kemik içeren gidalar } \\
\text { Bone-containing foods } \\
\text { such as meat, fish, } \\
\text { chicken, seafood }\end{array}$ & $\begin{array}{l}\text { EN 1786:1998 G1da Maddeleri - Issınlanmiş, Kemik } \\
\text { İçeren Gidalarn Tespiti - ESR Spektroskopi } \\
\text { Yöntemi EN 1786:1998 Foodstuffs - Detection of } \\
\text { irradiated food containing bone - Method by ESR } \\
\text { spectroscopy }\end{array}$ & $\begin{array}{l}\text { Fiziksel } \\
\text { Physical }\end{array}$ \\
\hline 3 & $\begin{array}{lr}\text { Selüloz } & \text { içeren } \\
\text { g1dalar } & \\
\text { Foods } & \text { containing } \\
\text { cellulose } & \end{array}$ & $\begin{array}{l}\text { EN 1787:2005 Gida Maddeleri - Selüloz İçeren } \\
\text { Işınlanmış G1daların ESR Spektroskopisi ile } \\
\text { Belirlenmesi Yöntemi } \\
\text { EN 1787:2005 Foodstuffs - Detection of irradiated food } \\
\text { containing cellulose - Method by ESR spectroscopy }\end{array}$ & $\begin{array}{l}\text { Fiziksel } \\
\text { Physical }\end{array}$ \\
\hline 4 & $\begin{array}{l}\text { Şeker içeren gidalar } \\
\text { Foods containing } \\
\text { sugar }\end{array}$ & $\begin{array}{l}\text { EN 13708:2004 Gıda Maddeleri - Kristal Şeker } \\
\text { İçeren G1daların Işınlanıp Işınlanmadığının ESR } \\
\text { Spektroskopisi ile Belirlenmesi Yöntemi } \\
\text { EN 13708:2004 Foodstuffs - Detection of irradiated food } \\
\text { containing crystalline sugar by ESR spectroscopy }\end{array}$ & $\begin{array}{l}\text { Fiziksel } \\
\text { Physical }\end{array}$ \\
\hline 5 & $\begin{array}{l}\text { Et, süt ürünleri, su } \\
\text { ürünlerive meyveler } \\
\text { gibi katı yă̆ içeren } \\
\text { gidalar } \\
\text { Fat-containing foods } \\
\text { such as meat, dairy } \\
\text { products, seafood, and } \\
\text { fruits }\end{array}$ & $\begin{array}{l}\text { TS EN 1784:2005 Gida Maddeleri - Katı Yağ } \\
\text { İçeren Işınlanmış Gidaların Belirlenmesi - } \\
\text { Hidrokarbonlann Gaz Kromatografik Analizi } \\
\text { Yöntemi } \\
\text { TS EN 1784:2005 Foodstuffs - Detection of irradiated } \\
\text { food containing fat - Gas chromatographic analysis of } \\
\text { bydrocarbons }\end{array}$ & $\begin{array}{l}\text { Kimyasal } \\
\text { Chemical }\end{array}$ \\
\hline
\end{tabular}




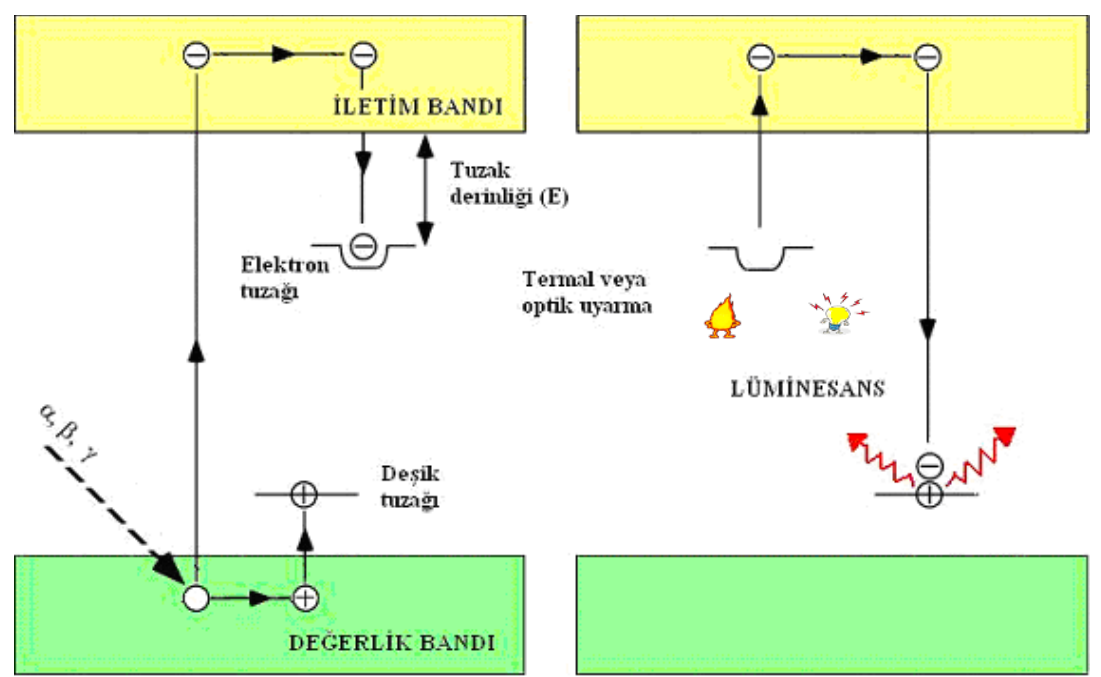

Şekil 2. Lüminesans olayının enerji bant diyagramı (Yüce, 2010)

İletim bandi: Conduction band

Figure2. Energy band diagram of luminescence event (Yüce, 2010)

Değerlik bandı: Valance band

Tuzak derinliği: Trap depth

Elektron tuzağı: Electron trap

Termal veya optik uyarma. Thermal or optical stimulation

Lüminesans: Luminescence

Deşik tuzağı: Hole trap

Gıda ışınlama sırasında kullanılan radyasyon iyonize etme özelliğine sahiptir. Gidalar ışınlandığında eğer üzerlerinde silikat mineralleri var ise bu minerallerin değerlik bandındaki elektronlar iyonizasyon sonucu iletim bandina geçerler. Burada çok kısa süre kaldıktan sonra (pikosaniyeler mertebesinde) hemen iletim bandına en yakın tuzaklarda depolanırlar. İyonize edilen elektronların geride biraktıkları boşluklar olan deşikler de değerlik bandına en yakın tuzaklarda depolanırlar. Böylece radyasyon enerjisi, minerallerin kristal yapısında geçici olarak depo edilir ve sistem yan kararlı bir halde kalır. Sistemin kararlı hale gelebilmesi için elektronların bu tuzaklardan çıkarılması bunun için sisteme dışarıdan 1s1, 1şık vb. bir enerji verilmesi gerekmektedir. Termolüminesans olayında kristalin 1sıtulması ile yeterli enerjiyi (tuzaktan kaçmak için gerekli eşik enerjisini) alan elektronlar, tuzaklardan kurtularak tekrar iletim bandına geçer. İletim bandında yine çok kısa süre kaldıktan sonra geride bıraktıkları deşiklerin tuzaklandığ1 enerji seviyelerine geçiş yaparlar. Her bir elektronun geçişi sırasında görünür bölgede lüminesans 1şımalar açığa çıkar. İşte bu lüminesans 1şımalar, 1S1 enerjisi verilerek gerçekleştiği için bu olaya Termolüminesans denir (Aitken, 1985; Yüce, 2010).

Gıda üzerine yapışmış silikat minerallerinin TL ölçümleri yapılırken mineraller genellikle $500^{\circ} \mathrm{C}$ sicaklığa kadar sabit bir 1sitma hizında 1sitlir. Yayınlanan lüminesansın şiddeti hassas bir foto çoğaltıcı tüp yardımı ile ölçülerek sıcaklığın bir fonksiyonu şeklinde kaydedilir. Bir TL sinyali, farklı sıcaklıklarda belirgin piklerin gözlendiği bir ışıma eğrisi (glow curve) ile değerlendirilir. Işıma eğrisinde görülen bu pikler, 1sittlan mineralin içerisindeki elektron tuzakları boşaldıkça önce artş̧ gösterir sonra o enerji seviyesindeki tuzakların tamamı boşaldığı için lüminesans ışımanın giderek azalmasıyla yavaşça sıfirlanır. Sicaklık arttıkça elektronlar daha çok enerji alabildiği için daha derin (yani elektronları çıartmak için daha çok enerji gerektiren) tuzaklardaki elektronlar uyarllır ve lüminesans şiddet tekrar artar ve yine o tuzak seviyesi boşalınca tekrar sıfırlanır. Bu durum sıcaklik arttıkça mevcut tuzakların derinliğine yani enerjisine göre hiç dolu tuzak kalmayıncaya kadar 
devam eder. Böylece TL 1şıma eğrisindeki pikler Şekil 3'deki gibi sürekli bir şekilde sıra sıra dizilir (Aitken, 1985;Yüce, 2010).

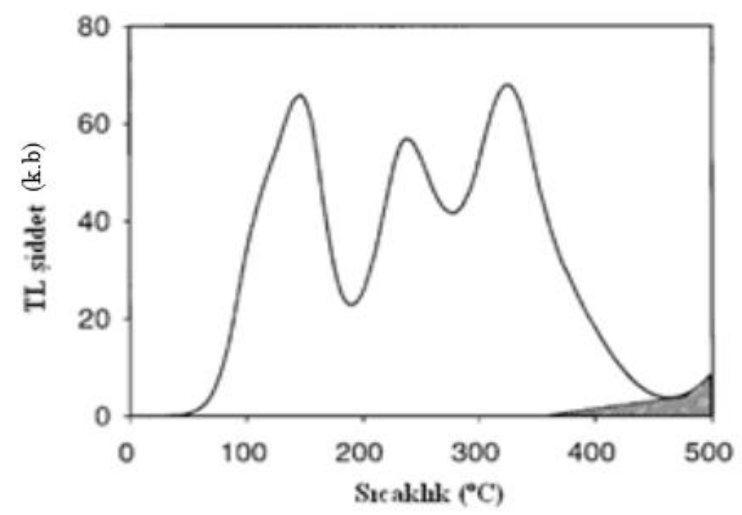

Şekil 3. Toprak örneğinden çıkarılan feldspat mineralinin TL 1şıma eğrisi (Aitken, 1985)

Figure3. TL glow curve of feldspar mineral extracted TL şiddet: TL intensity from soil sample (Aitken, 1985)

S1caklık: Temperature

\section{EN1788 standardinın uygulanmas1}

G1da maddeleri üzerindeki inorganik toz zerrecikleri çoğunlukla kuvars ve feldspat minerallerinden oluşur. İyi birer lüminesans materyal olan bu mineraller silisyum tabanl1 oldukları için silikat mineralleri olarak adlandırılır. Doğal olarak bilinen 11 feldspat olmasina rağmen doğada en çok bulunan feldspat çeşitleri potasyum feldspat $\left(\mathrm{KAlSi}_{3} \mathrm{O}_{8}\right)$, sodyum feldspat $\left(\mathrm{NaAlSi}_{3} \mathrm{O}_{8}\right)$ ve kalsiyum feldspat $\left(\mathrm{CaAlSi}_{2} \mathrm{O}_{8}\right)$ 'dır. Bu feldspat türlerinin yoğunlukları 2.5-2.6 $\mathrm{g} / \mathrm{cm}^{3}$ arasında değişmektedir. Kuvars minerali ise silisyum dioksit $\left(\mathrm{SiO}_{2}\right)$ kimyasal formuna sahiptir ve yoğunluğu 2.65-2.66 $\mathrm{g} / \mathrm{cm}^{3}$ arasindadır. Bu minerallerden etkin bir lüminesans elde edebilmek için lüminesans sinyal vermeyecek olan karbonatların ve gıdanın organik kısımlarının ölçüm yapılacak örnekten uzaklaştırılması gerekir.

Silikat minerallerini gidalardan ayrışurma işlemleri TS EN 1788:2007 standardında ayrintili bir şekilde anlatulır. Bu yöntem, baharatlar, şifalı bitkiler, bunların karışımları, kabuklu deniz hayvanlanı, taze ve kurutulmus meyve sebzeler kısacası üzerinde silikat minerali bulunan ve bu minerallerin ayrışturılabildiği gidalara başarıyla uygulanabilir (TS EN 1788:2007).

$\mathrm{Bu}$ çalışmada tarçın, köri, yeşil mercimek, kurutulmuş mantar, ay çekirdeği, keklik otu ve yeşil çay örneklerinin herhangi bir işınlama işlemine maruz kalıp kalmadı̆̆ Termolüminesans tekniği ile TS EN 1788:2007 (G1da MaddeleriSilikat Minerallerinin Ayrılabildiği Gıdalarda Işınlamanın Belirlenmesi-Termolüminesans Yöntemi) standardı temel alınarak araştırılmıştır. Örneklerden yukarıdaki standarda göre ayrıştırılan silikat minerallerinin önce doğal termolüminesans ışıma eğrilerine (TL1) daha sonra aynı örneklerin 1 kGy beta dozu aldiktan sonraki termolüminesans 1şıma eğrilerine (TL2) bakılmıştır. TL1 ve TL2 1şıma eğrilerinin şekilleri ve altında kalan alanların oranları (TL1/TL2) değerlendirilerek örneklerin 1şınlanmış veya ışınlanmamış olduğuna karar verilmiştir.

\section{Minerallerin ayrıştırılması}

Tüm gıda örnekleri ayrı ayr1 1000 ml'lik beherlere konuldu. Örnekler beherlere konulurken örneklerin bulunduğu şeffaf plastik poşetlerin dip kisımlarında kalan toz zerrecikleri de beherlere aktarıldı. Şeffaf poşetlerden aktarılması zor olan yapışmış toz zerrecikleri ise su yardımıyla poşetlerden beherlere akıtıldı. Gıdalara yapışan toz zerreciklerinin gidalardan ayrilabilmesini kolaylaştırmak için beherlerin üzerleri de-iyonize su ile doldurulduktan sonra ultrasonik banyoda bir saat titreşimde bekletildi. Daha sonra her bir örnek için ayrı naylon elek kullanılarak tüm örnekler ayrı ayrı derin kaplara süzüldü. Eleklerin üzerinde kalan örnekler püskürtme mekanizması olan bir su bataryası yardımıyla de-iyonize su ile yıkandi. Bu işlemlerden sonra toz taneciklerinin derin kaplann diplerine çökmesi için iki saat beklendi ve toz tanecikleri kaplarnn diplerinde kalacak şekilde üstte kalan sulu kısımlar döküldü. Böylece 250 mikronluk naylon elek yardımıyla yeşil mercimek, kurutulmuş mantar, ay çekirdeği, keklik otu ve yeşil çay gibi büyük parçalı g1da kalıntıları kolayca temizlenebildi. Tarçın ve köri örnekleri içinse 125 mikronluk naylon elek kullanıldı. Ancak bu iki baharat örneği küçük tanecikli olduğu için dipte kalan mineralli su içinde 
oldukça fazla gida kalıntısının mevcut olduğu görüldü.

Derin kapların diplerinde kalan mineralli su karışımları her örnek için 8 ayrı santrifüj tüpüne paylaştırılarak ivmesi $1000 \mathrm{~g}$ olacak şekilde 2 dakika santrifüjlendi. Bu işlem sonucu yoğunluğu $1 \mathrm{~g} / \mathrm{ml}$ ' den az olan istenmeyen organik kısımlar tüplerin üst kısımlarında kalmıs oldu. Tüplerin üzerindeki sular boşaltılarak tüplere yoğunluğu 2.0 $\mathrm{g} / \mathrm{ml}$ olan lityum heteropolitungstate (LST) ağır sıvı ayrışturıcısı eklendi. Örnekler 2 dakika santrifüjlendikten sonra LST üzerinde kalan organik kalıntılar pastör pipet yardımıla alındı. Tüplerin içinde kalan LST, pastör pipet yardımıyla tüplerin diplerinde kalan minerallere zarar vermeden dikkatli bir şekilde alındi. Örnekleri LST' den arındırmak için tüplere saf su konuldu ve LST kalıntıları temizlenene kadar birkaç kez saf su ile santrifüj işlemi yapıldı. Bu işlemler her bir gıda için ayrı ayrı tekrarlandı. Tarçın ve köri hariç tüm örneklerdeki organik kalıntılar tek seferde kolayca temizlenebildi. Tarçın ve köri için LST ile aynı işlem organik gıda kalıntılarından kurtuluncaya kadar tekrarlandi.

Numuneyi karbonatlardan arındırmak için, tüplere pastör pipet yardımıla $1 \mathrm{M}, 5 \mathrm{ml}$ hidroklorik asit (HCI) çözeltisi ilave edildi ve 10 dakika karanlık ortamda bekletildi. HCI 'yi nötralize etmek için tüplere $1 \mathrm{M}, 5 \mathrm{ml}$ amonyum hidroksit $\left(\mathrm{NH}_{4} \mathrm{OH}\right)$ çözeltisi ve kalan boşluğ da saf su eklendi. Bu karışım 2 dakika santrifüjlendi. Her aşamada tüplerin diplerinde kalan mineralleri kaybetmemek için minerallerin üzerlerindeki fazla su ve kimyasallar pastör pipet yardımıyla dikkatli bir şekilde alındı. Son olarak silikat minerallerini kimyasal kalıntılardan arındırmak için tüplere aseton konuldu ve 1 dakika santrifüjlendi. Aseton ile santrifüj işlemi aseton berraklaşana kadar tekrar edildi. Tüplerdeki aseton yine bir pastör pipet yardımıyla boşaltılarak tüplerin diplerinde kalan silikat mineralleri ayr1 ayr1 petri kaplarına konuldu. Silikat minerallerinin olduğu petri kaplan $45^{\circ} \mathrm{C}$ de 5 saat süreyle etüvde kurutularak ölçüme hazır hale getirildi. Bu işlemler her bir gıda için ayrı ayrı tekrarlandı.
Örnekler kurutulduktan sonra petri kaplarına yapışmış olanlar bir spatül yardımıyla kazınarak her örnek için yaklaşık $10 \mathrm{mg}$ silikat minerali toplanabildi. Ay çekirdeği örneğinden minerallerin ayrıştırılması işlemi sırasında yeterince silikat minerali toplanamadığ1 görüldü. Yine de olan az miktarı (yaklaşık $3 \mathrm{mg}$ ) ile deneylere devam edildi.

\section{Termolüminesans ölçümleri}

Ölçümler 7,5 mm kalınlı̆̆ında Hoya U-340 filtresi yerleştirilmiş Riso TL/OSL Model DA- 20 okuyucuda kırmızı 1şıkla aydınlatılan laboratuvar şartlarında yapıldı. Işı1k dedeksiyonu maksimum dedeksiyon etkinliği 300-400 nm aralı̆̆ında olan bialkali EMI 9235QA foto çoğaltıcı tüp ile gerçekleştirildi. $70-500{ }^{\circ} \mathrm{C}$ sıcaklık aralığında 6 ${ }^{\circ} \mathrm{C} /$ sn 1sitma hizinda ve sivi azot atmosferinde TL sinyallerine bakıldı. Bu işlem sırasında sahte TL piklerini ve hızlı 1sınma-soğumaları engellemek için \%99.99 yüksek saflıkta azot gazı (nitrojen) kullanıldı. TL ölçümleri paslanmaz çelikten yapılmış dış çap1 $12 \mathrm{~mm}$, iç çap1 $9 \mathrm{~mm}$ ve yüksekliği $1 \mathrm{~mm}$ olan TL kaplarına yaklaşık $5 \mathrm{mg}$ örnek konularak yapıldı. Ölçüm yapılan TL kapları ve örnek tutucu deneylere başlamadan önce herhangi bir kalıntı olması ihtimaline karşı alkol ile temizlendi.

Her ölçümden önce boş TL kaplarının ışıma eğrileri kaydedildi. Şekil 4’te verilen boş ölçüm kabının TL ışıma eğrisine bakıldığında ölçümleri olumsuz etkileyebilecek herhangi bir TL sinyali gözlenmemiştir. Ardından aynı okuma şartlarında yaklaşık $5 \mathrm{mg}$ silikat mineralinin bulunduğu ölçüm kaplarının TL1 okumaları yapıldı. TL1 1şıma eğrisi kaydedilen örnekler normalizasyon amaciyla Sr-90 beta kaynağ1 kullanılarak 1 kGy 1şınlandı. Işınlamadan sonra örneklerdeki sı̆̆ tuzakların boşaltılabilmesi yani düşük sıcaklıklarda kafa karıştracak TL sinyallerinin sönümlenmesi için etüvde 1 gece boyunca $50^{\circ} \mathrm{C}$ sicaklikta bekletildi. $\mathrm{Bu}$ örneklerin ölçümleri alındı ve TL2 olarak kaydedildi.

\section{Işınlanma ve 1şınlanmama kararı}

TS EN1788:2007 standardına göre 1şınlanmış gidalar $150-250{ }^{\circ} \mathrm{C}$ sicaklık aralı̆̆ında bir pik verirken 1şınlanmamış örnekler düşük seviyede 
(bir yılda yaklaşık 1-2 mGy civarında) radyoaktivitenin neden olduğu 250-300 ${ }^{\circ} \mathrm{C}$ 'nin üzerinde TL pikleri verirler. Düşük seviyede radyoaktivite, silikat minerallerinin kendi içerisinde ve çevresinde bulunan radyoaktif maddelerden (çoğunlukla Uranyum-238,
Toryum-232 ve Potasyum-40) kaynaklanir. Yine bu standartta $150-250{ }^{\circ} \mathrm{C}$ sicaklık aralığında TL1 ve TL2 ışıma eğrilerinin altında kalan alanların oranı (TL1/TL2), ışınlanmış örneklerde 0,5'ten büyükken 1şınlanmamış örneklerde $0,1^{\prime}$ in çok altında olduğu belirtilmektedir.

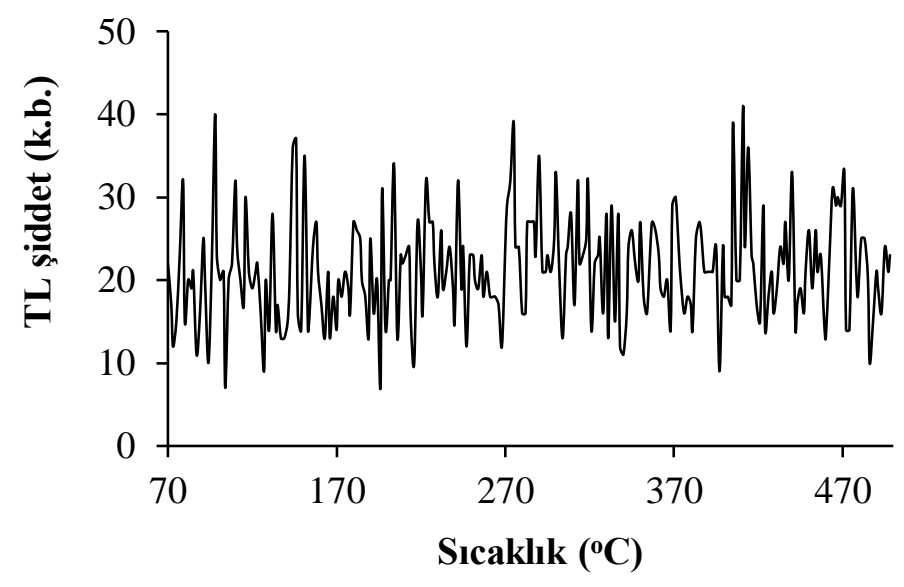

TL şiddet: TL intensity (a.u)

Şekil 4. Boş ölçüm kabının TL 1şıma eğrisi.

Figure 4. TL glow curve of the empty TL cup.

Sicaklik : Temperature

\section{SONUÇLAR VE TARTIŞMA}

İncelenen örneklerin TL1 ve TL2 1şıma eğrileri Şekil 5-11'de görülmektedir. Bu eğrilere ait pik maksimum şiddet ve pik maksimum sicaklık değerleri, TL1/TL2 oranları ve ışınlanmış olup olmadıklarının sonuçları Çizelge 2'de verilmiştir.

Yeşil çay örneğinin TL1 1şıma eğrisi olan Şekil 5a'ya bakıldığında $302^{\circ} \mathrm{C}$ sicaklıkta maksimumu olan düşük şiddetli bir doğal radyasyon sinyali gözlenirken normalizasyon ışınlamasından sonra kaydedilen TL2 1şıma eğrisinde maksimumu $208^{\circ} \mathrm{C}$ sıcaklıkta olan oldukça yüksek şiddetli bir sinyal gözlenmiştir (Şekil 5b) . Çizelge 2'de yeşil çay için verilen TL1/TL2 oranına bakıldı̆̆ında 0.002 gibi oldukça düşük bir oran görülmektedir. Elde edilen bu verilerden yola çıkılarak yeşil çay örneğinin ışınlanmamış olduğu sonucuna varılmıştır.
Keklik otu ömeği $206{ }^{\circ} \mathrm{C}$ sicaklıkta pik maksimumu olan bir TL1 1şıma eğrisine ve $227^{\circ} \mathrm{C}$ sıcaklıkta pik maksimumu olan yüksek şiddetli bir TL2 1şıma eğrisine sahiptir (Şekil 6). TL1/TL2 oranı ise cihazda otomatik alan değeri hesaplamalar1 ile 0.415 olarak belirlenmiştir (Çizelge 2) . Bu sonuçlardan yola çıkılarak keklik otu örneğinin ışınlanmış olduğu söylenebilir.

Şekil 7 ve Şekil 8'de verilen kurutulmuş mantar ve ay çekirdeği örneklerine ait TL 1şıma eğrilerinin şekillerine ve Çizelge 2'de verilen TL1/TL2 oranlarına bakılarak her iki örneğin ışınlanmış olduğu sonucuna varılmıştır. Şekil 9, 10 ve 11 'de verilen yeşil mercimek, tarçın ve köri örneklerinin TS EN1788:2007 standardına göre tavsiye edilen $150-250^{\circ} \mathrm{C}$ sicaklık aralı̆̆ında TL1 ve TL2 1şıma eğrilerinin integralleri alındıktan sonra belirlenen TL1/TL2 oranlar1 0,1 den büyük bulunmuştur. Her üç örneğin de ş̧ınlanmış olduğu sonucuna varilmıştır. 
Çizelge 2. Örneklere ait ışıma eğrilerinin özellikleri

Table 2. Properties of radiation curves of samples.

\begin{tabular}{|c|c|c|c|c|}
\hline $\begin{array}{ll}\text { Örnek } & \text { adı } \\
\text { Sample } & \end{array}$ & $\begin{array}{l}\text { TL1 } \\
\text { TL1 }\end{array}$ & $\begin{array}{l}\text { TL2 } \\
\text { TL2 }\end{array}$ & $\begin{array}{l}\text { TL1/TL2 } \\
\text { TL1/TL2 }\end{array}$ & $\begin{array}{l}\text { Sonuç } \\
\text { Result }\end{array}$ \\
\hline $\begin{array}{l}\text { Yeşil Çay } \\
\text { Green tea }\end{array}$ & $\begin{array}{l}\mathrm{T}_{\max }=302 \circ \mathrm{C} \\
\mathrm{I}_{\max }=271\end{array}$ & $\begin{array}{l}\mathrm{T}_{\max }=208^{\circ} \mathrm{C} \\
\mathrm{I}_{\max }=115957\end{array}$ & 0.002 & $\begin{array}{l}\text { Işınlanmamış } \\
\text { Not irradiated }\end{array}$ \\
\hline $\begin{array}{l}\text { Keklik Otu } \\
\text { Oregano }\end{array}$ & $\begin{array}{l}\mathrm{T}_{\max }=206^{\circ} \mathrm{C} \\
\mathrm{I}_{\max }=18831\end{array}$ & $\begin{array}{l}\mathrm{T}_{\max }=227 \circ \mathrm{C} \\
\mathrm{I}_{\max }=45427\end{array}$ & 0.415 & $\begin{array}{l}\text { Işınlanmış } \\
\text { Irradiated }\end{array}$ \\
\hline $\begin{array}{l}\text { Kurutulmuş } \\
\text { Mantar } \\
\text { Dried Mushroom }\end{array}$ & $\begin{array}{l}\mathrm{T}_{\max }=227 \circ \mathrm{C} \\
\mathrm{I}_{\max }=38313\end{array}$ & $\begin{array}{l}\mathrm{T}_{\max }=163{ }^{\circ} \mathrm{C} \\
\mathrm{I}_{\max }=106064\end{array}$ & 0.362 & $\begin{array}{l}\text { Işınlanmış } \\
\text { Irradiated }\end{array}$ \\
\hline $\begin{array}{l}\text { Ay Çekirdeği } \\
\text { Sunflower seeds }\end{array}$ & $\begin{array}{l}\mathrm{T}_{\max }=218{ }^{\circ} \mathrm{C} \\
\mathrm{I}_{\max }=14100\end{array}$ & $\begin{array}{l}\mathrm{T}_{\max }=159 \circ \mathrm{C} \\
\mathrm{I}_{\max }=33205\end{array}$ & 0.425 & $\begin{array}{l}\text { Işınlanmış } \\
\text { Irradiated }\end{array}$ \\
\hline $\begin{array}{l}\text { Yeşil Mercimek } \\
\text { Green lentils }\end{array}$ & $\begin{array}{l}\mathrm{T}_{\max }=237 \circ \mathrm{C} \\
\mathrm{I}_{\max }=3108\end{array}$ & $\begin{array}{l}\mathrm{T}_{\max }=225^{\circ} \mathrm{C} \\
\mathrm{I}_{\max }=7032\end{array}$ & 0.442 & $\begin{array}{l}\text { Işınlanmış } \\
\text { Irradiated }\end{array}$ \\
\hline $\begin{array}{l}\text { Tarçin } \\
\text { Cinnamon }\end{array}$ & $\begin{array}{l}\mathrm{T}_{\max }=225^{\circ} \mathrm{C} \\
\mathrm{I}_{\max }=165332\end{array}$ & $\begin{array}{l}\mathrm{T}_{\max }=199 \circ \mathrm{C} \\
\mathrm{I}_{\max }=153247\end{array}$ & 1.079 & $\begin{array}{l}\text { Işınlanmiş̧ } \\
\text { Irradiated }\end{array}$ \\
\hline $\begin{array}{l}\text { Köri } \\
\text { Curry }\end{array}$ & $\begin{array}{l}\mathrm{T}_{\max }=225 \circ \mathrm{C} \\
\mathrm{I}_{\max }=62917\end{array}$ & $\begin{array}{l}\mathrm{T}_{\max }=185 \circ \mathrm{C} \\
\mathrm{I}_{\max }=66347\end{array}$ & 0.948 & $\begin{array}{l}\text { Işı1nlanmış } \\
\text { Irradiated }\end{array}$ \\
\hline
\end{tabular}

$\mathrm{T}_{\max }=$ Maksimum pik sıcaklığı $\mathrm{I}_{\max }=$ Maksimum pik şiddeti

Tmax $=$ Maximum peak temperature, Imax $=$ Maximum peak intensity

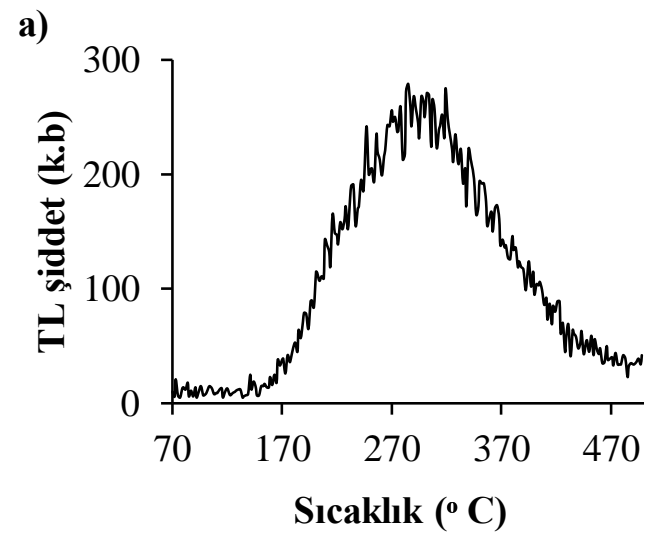

b)

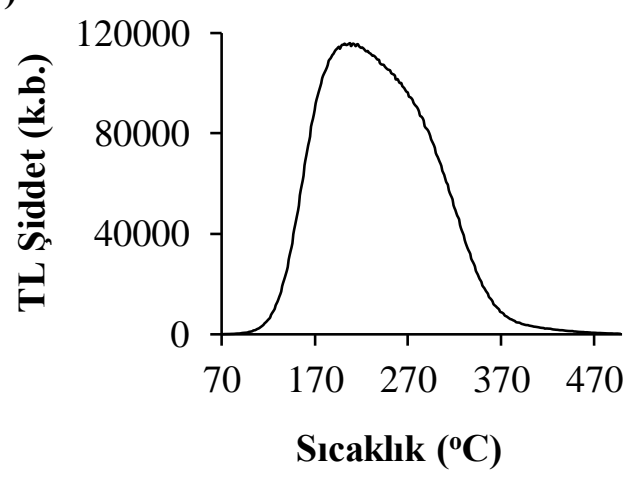

Şekil 5. Yeşil çay örneğinin a) 1şınlanmamış (TL1 ) ve b) 1 kGy ş̧ınlanmış (TL2) 1şıma eğrileri.

TL şiddet: TL intensity (a.u)

Figure 5. TL1 and TL2 glow curves of green tea sample.

Sicaklik : Temperature

1 kGy 1şınlanmış (TL1): 1 kGy irradiated (TL1)

Işınlanmamış: Not irradiated (TL2) 


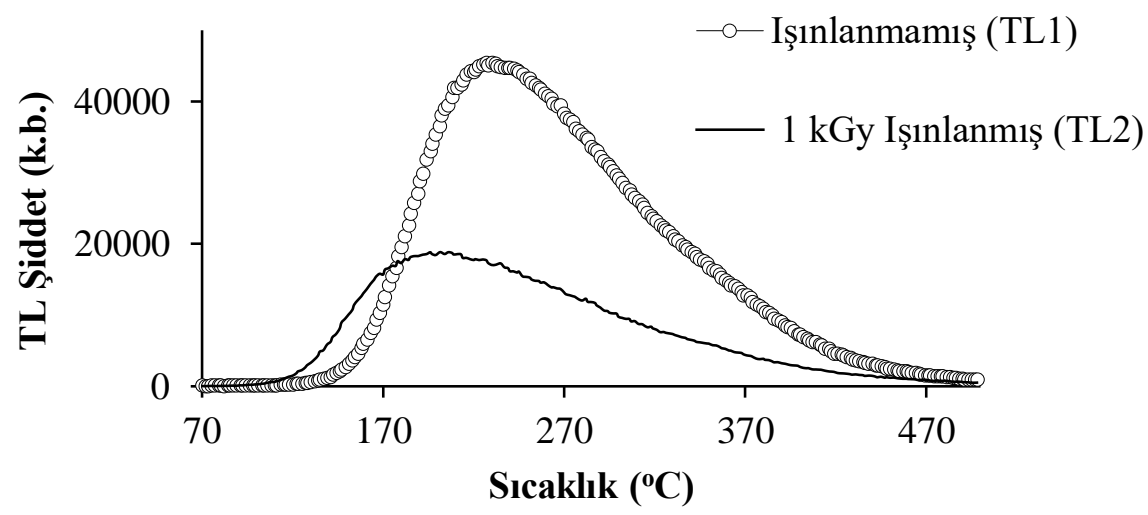

Şekil 6. Keklik otu örneğinin TL1 ve TL2 1şıma eğrileri.

TL şiddet: TL intensity (a.u)

Figure 6. TL1 and TL2 glow curves of oregano sample.

Sicaklık: Temperature

1 kGy 1şınlanmış (TL1): 1 keGy irradiated (TL1)

Işınlanmamış: Not irradiated (TL2)

Elde edilen tüm sonuçlar, literatürde daha önce Termolüminesans tekniği kullanılarak belirlenen ı̧̧ınlanmış ve ışınlanmamış gida ayırımları ile uyum içindedir (Engin 2007; Paksu vd. 2013; Cam vd. 2012).

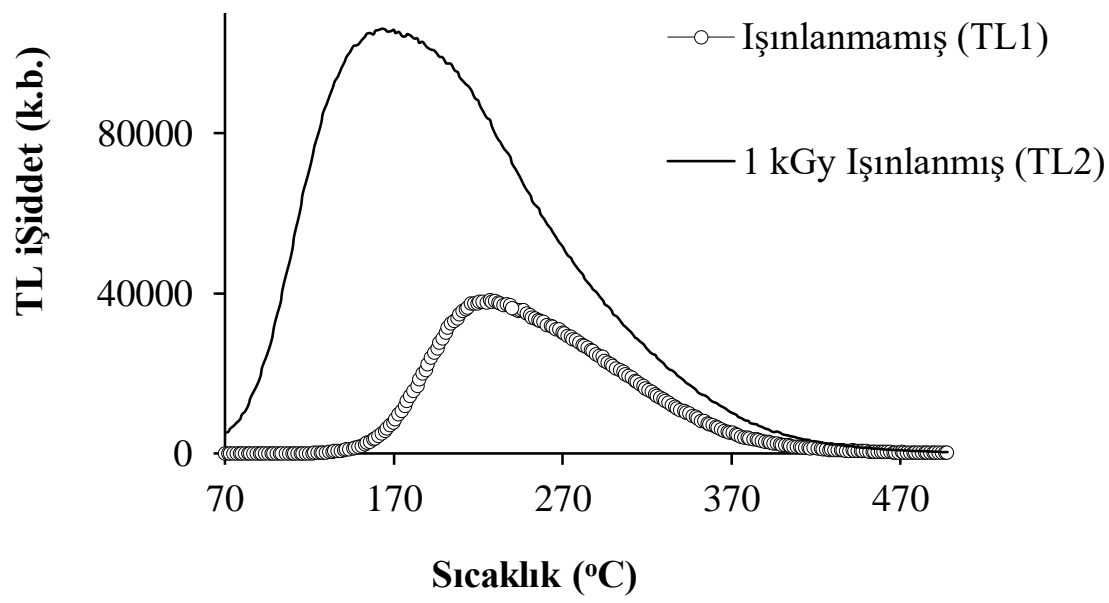

TL şiddet: TL intensity (a.u)

Şekil 7. Kurutulmuş mantar örneğinin TL1 ve TL2 ışıma eğrileri. Figure 7. TL1 and TL2 glow curves of dried mushroom sample.

Sicaklik : Temperature

1 kGy 1şınlanmış (TL1): 1 keGy irradiated (TL1)

Işınlanmamış: Not irradiated (TL2) 


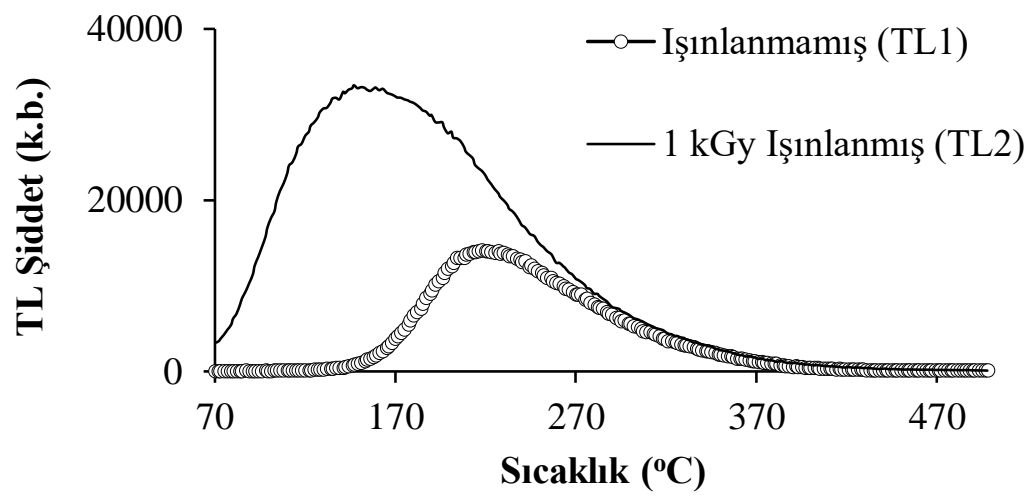

TL şiddet: TL intensity (a.u)

Şekil 8. Ay çekirdeği örneğinin TL1 ve TL2 1şıma eğrileri.

Figure 8. TL1 and TL2 glow curves of sunflower seeds sample.

Sicaklik : Temperature

1 kGy ışınlanmış (TL1): 1 kGy irradiated (TL1)

Işınlanmamış: Not irradiated (TL2)

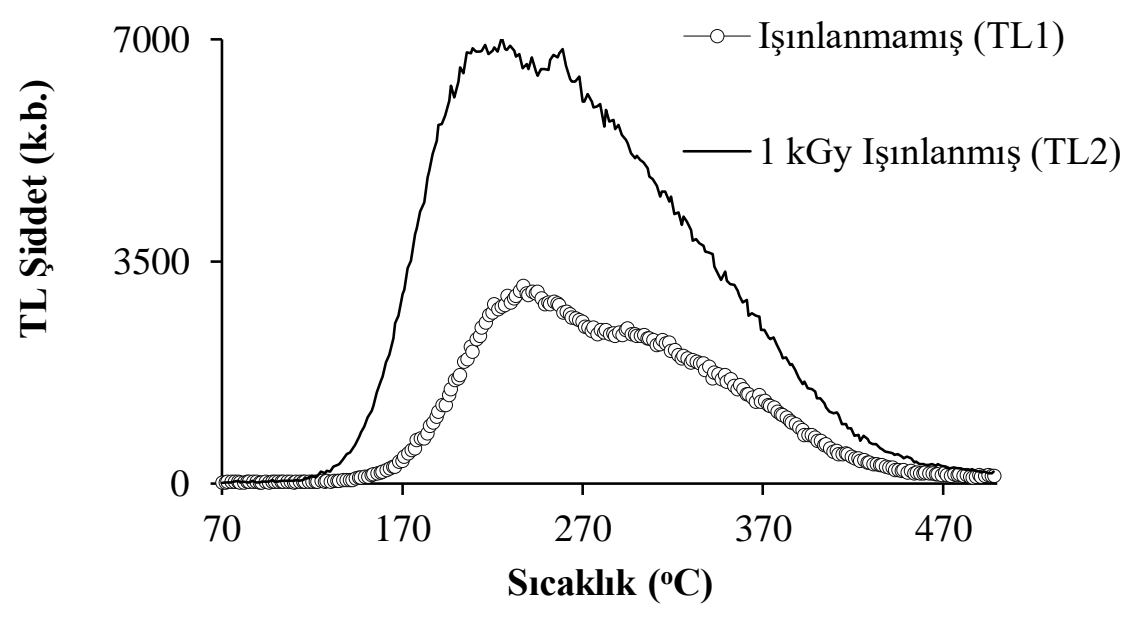

Şekil 9. Yeşil mercimek örneğinin TL1 ve TL2 1şıma eğrileri.

Figure 9. TL1 and TL2 glow curves of green lentils sample.

TL şiddet: TL intensity (a.u)

Sicaklik : Temperature

1 kGy ışınlanmış (TL1): 1 kGy irradiated (TL1)

Işınlanmamış: Not irradiated (TL2) 


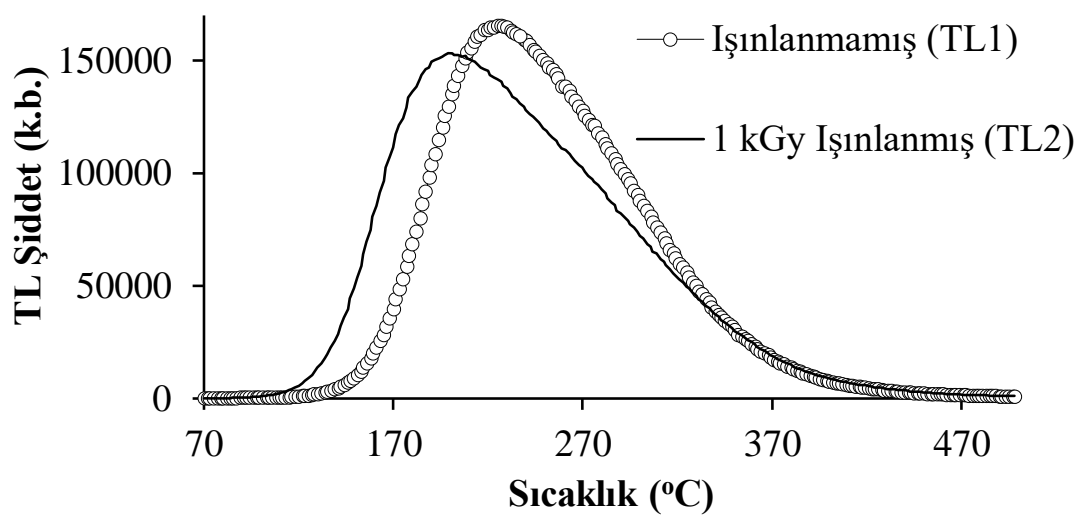

TL şiddet: TL intensity (a.u)

Şekil 10. Tarçın örneğinin TL1 ve TL2 1şıma eğrileri.

Figure 10. TL1 and TL2 glow curves of cinnamon sample.

Sicaklik : Temperature

1 kGy 1şınlanmış (TL1): 1 kGy irradiated (TL1)

Işınlanmamış: Not irradiated (TL2)

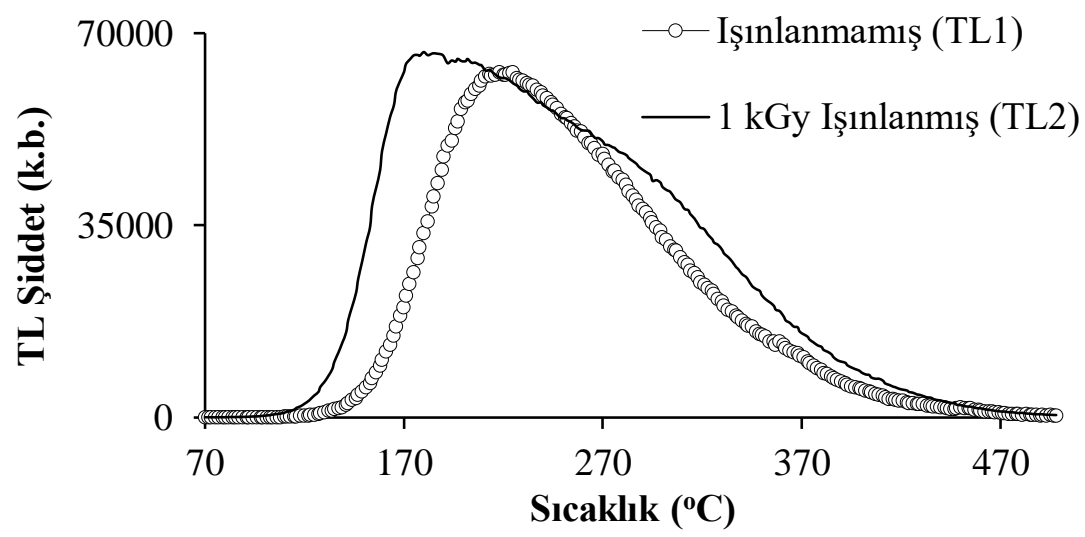

Şekil 11. Köri örneğinin TL1 ve TL2 1 şıma eğrileri.

TL şiddet: TL intensity (a.u)

Figure 11. TL1 and TL2 glow curves of curry sample.

Sicaklik : Temperature

1 kGy 1şınlanmış (TL1): 1 kGy irradiated (TL1)

Işınlanmamış: Not irradiated (TL.2)

TL tekniği ile ışınlanmış gıda tespiti çalışmalarında TL2 ölçümleri için yapılan normalizasyon 1şınlamaları çoğunlukla Co-60 gama kaynağı ile yapılmaktadır. Bu çalışmada bir gama kaynağı yerine Sr-90 beta kaynağından çıkan beta ışınları kullanılmış ve karşılaştırma çalışması sonuç raporlarında, tüm örneklerin \%100 başarı ile "ışınlanmış" veya "1şınlanmamış" olarak tespit edildiği belirtilmiştir.

\section{ÇIKAR ÇATIŞMASI BEYANI}

Yazarlar, bu makale ile ilgili başka kişi veya kurumlar ile çıkar çatışması olmadığını beyan eder.

\section{YAZAR KATKILARI}

Dr. Ülkü Rabia YÜCE SEMİ: \%70

Talat AYDIN: $\% 30$ 


\section{KAYNAKLAR}

Aitken, M.J.(1985). Thermoluminescence dating. Academic Press, Orlando/London, 351 p.

Anonymous (1981). Wholesomeness of irradiated food, Report of joint FAO/IAEA/WHO Expert Commitiee World Health Organisation, Geneva. Technical Report Series 659.

Bayram, G., Delincee, H. (2004). Identification of irradiated Turkish foodstuffs combining various physical detection methods. Food Control 15: 8191, https:// doi.org/10.1016/S09567135(03)00018-5.

Çam, S. T., Aydaş, C., Engin, B., Yüce, U.R. , Aydin, T., Polat, M. (2012). ESR and TL studies of irradiated Anatolian laurel leaf (Laurus nobilis L.), Radrat. Eff. Defect S. 167 (6): 1-11, https://doi:10.1080/10420150.2012.666243.

EN 1786 (1998). Detection of irradiated food containing bone: analysis by electron paramagnetic resonance. European Committee for Standardization, Brussels.

EN 13708 (2004). Detection of irradiated food containing crystalline sugar: analysis by EPR. European Committee for Standardization, Brussels.

EN 1787 (2005). Determination of irradiated food containing cellulose: analysis by EPR. European Committee for Standardization, Brussels.

EN 1788 (2007). Thermoluminescence detection of irradiated food from which silicate minerals can be isolated. European Committee for Standardization, Brussels.

Engin, B. (2007). Thermoluminescence parameters and kinetics of irradiated inorganic dust collected from black peppers. Food Control18:
243-250,

https://doi:10.1016/j.foodcont. 2005.10.002.

Engin, B., Aydaş, C., Yüce, Ü.R., Aydın, T., Çam, S.T., Demirtaş, H. ve Zeyrek, C.T. (2011). Elektron Spin Rezonans (ESR) ve Termolüminesans (TL) teknikleri ile gidaların gama ışınlanı ile ışınlanıp 1şınlanmadıklarının tespit edilmesi. (Teknik rapor, TAEK TR-2011-07). Ankara: Türkiye Atom Enerjisi Kurumu.

Gıda Işınlama Yönetmeliği (2019).

International Atomic Energy Agency (1991). Facts About Food Irradiation. Vienna, Austria. IAEA/PI/A33E.

Paksu, U, Aydaş, C. , Yüce, U.R., Aydın, T., Polat, M., Engin, B., (2013). ESR and TL investigations on gamma irradiated linden (Tilia vulgaris). Radiat. Environ. Biophys. 52(2) : 255-267, https://doi:10.1007/s00411-013-0465-x.

Schreiber G. A., Hele, N., Bögl, K.W. (1993). Dedection of irradiated food-methods and routine applications. J.Radiat.Biol. 63: 105-130, https://doi.org/10.1080/09553009314550141.I

TS EN 1784 (2005). G1da Maddeleri - Katı Yağ İçeren Işınlanmış Gıdaların Belirlenmesi Hidrokarbonların Gaz Kromatografik Analizi Yöntemi.

Yüce,U.R. (2010). Diş ve kemik örneklerinin lüminesans tekniklerde geriye dönük (retrospektif) dozimetre olarak kullanımının geliştirilmesi. Ankara Üniversitesi Fen Bilimleri Enstitüsü Fizik Mühendisliği Anabilim Dalı Doktora Tezi, Ankara, Türkiye, 96s. 